\title{
Comparative Analysis of the Dalat Nuclear Research Reactor with HEU Fuel Using SRAC and MCNP5
}

\author{
Giang Phan, ${ }^{1}$ Hoai-Nam Tran, ${ }^{2}$ Kien-Cuong Nguyen, ${ }^{3}$ Viet-Phu Tran, ${ }^{4}$ Van-Khanh Hoang, \\ Pham Nhu Viet Ha, ${ }^{4}$ and Hoang Anh Tuan Kiet ${ }^{2,5}$ \\ ${ }^{1}$ Faculty of Applied Sciences, Ton Duc Thang University, Ho Chi Minh City 700000, Vietnam \\ ${ }^{2}$ Institute of Fundamental and Applied Sciences, Duy Tan University, 3 Quang Trung, Da Nang 550000, Vietnam \\ ${ }^{3}$ Nuclear Research Institute, VINATOM, 01 Nguyen Tu Luc, Dalat, Lamdong 670000, Vietnam \\ ${ }_{4}^{4}$ Institute for Nuclear Science and Technology, VINATOM, 179 Hoang Quoc Viet, Hanoi 100000, Vietnam \\ ${ }^{5}$ Western University Hanoi, Yen Nghia Ward, Ha Dong District, Hanoi 100000, Vietnam
}

Correspondence should be addressed to Giang Phan; phangiang@tdt.edu.vn and Hoai-Nam Tran; tranhoainam4@dtu.edu.vn

Received 7 June 2017; Revised 25 August 2017; Accepted 24 September 2017; Published 27 December 2017

Academic Editor: Arkady Serikov

Copyright (C) 2017 Giang Phan et al. This is an open access article distributed under the Creative Commons Attribution License, which permits unrestricted use, distribution, and reproduction in any medium, provided the original work is properly cited.

\begin{abstract}
Neutronics analysis has been performed for the $500 \mathrm{~kW}$ Dalat Nuclear Research Reactor loaded with highly enriched uranium fuel using the SRAC code system. The effective multiplication factors, keff, were analyzed for the core at criticality conditions and in two cases corresponding to the complete withdrawal and the full insertion of control rods. MCNP5 calculations were also conducted and compared to that obtained with the SRAC code. The results show that the difference of the keff values between the codes is within $55 \mathrm{pcm}$. Compared to the criticality conditions established in the experiments, the maximum differences of the keff values obtained from the SRAC and MCNP5 calculations are $119 \mathrm{pcm}$ and $64 \mathrm{pcm}$, respectively. The radial and axial power peaking factors are 1.334 and 1.710, respectively, in the case of no control rod insertion. At the criticality condition these values become 1.445 and 1.832 when the control rods are partially inserted. Compared to MCNP5 calculations, the deviation of the relative power densities is less than $4 \%$ at the fuel bundles in the middle of the core, while the maximum deviation is about $7 \%$ appearing at some peripheral bundles. This agreement indicates the verification of the analysis models.
\end{abstract}

\section{Introduction}

The TRIGA reactor, designed and manufactured by General Atomics (California, USA), is the most common research reactor with 66 facilities in 24 countries [1]. The TRIGA Mark II reactor is a pool-type multipurpose research reactor with the power range of $20 \mathrm{~kW}$ to $16 \mathrm{MW}$. In 1960s, the $250 \mathrm{~kW}$ TRIGA Mark II reactor was installed in Nuclear Research Institute located in Dalat, Vietnam. It is also the unique reactor of the country until present. In early 1980s, the reactor was upgraded to a $500 \mathrm{~kW}$ pool-type research reactor, named the Dalat Nuclear Research Reactor (DNRR). The feature of the DNRR is that the main structures of the TRIGA Mark II reactor were kept, except the active core zone. The core is loaded with the Russian VVR-M2 fuel type and cooled by natural convection. The first criticality of the DNRR was achieved on November 1, 1983, and the operation with full power was achieved in March 1984. During the period from 1984 to 2007 , the core was loaded with highly enriched uranium (HEU) fuel with ${ }^{235} \mathrm{U}$ enrichment of $36 \%[2,3]$. Then, the DNRR core was partly converted into low enriched uranium (LEU) fuel with ${ }^{235} \mathrm{U}$ enrichment of $19.75 \%$ in September 2007. The full-core conversion to LEU fuel was performed during the period from November 24, 2011, to January 13, 2012. At present, the operation of DNRR is mainly for radioisotope production, neutron activation analysis, education, and researches. The DNRR is operated in a continuous mode of about $100-130 \mathrm{hrs}$ in a period of 3-4 weeks. Then, the reactor is shut down for maintenance activities. During the maintenance, experimental physics researches are conducted. The yearly average operation time of the DNRR is about $1300 \mathrm{hrs}$ [3]. 
Similar to the TRIGA Mark II reactor, the DNRR consists of many components such as a neutron trap, water gaps, irradiation channels, horizontal beam ports, beryllium blocks, control rods, rotary specimen rack, and graphite reflector. These components make the core geometry complicated. Such a complicated geometry is only possible to be simulated using a Monte Carlo code. However, even in Monte Carlo simulation, possible modifications are usually made to simplify the core geometry [4]. Simplification and homogenization of complicated material regions outside the active core could usually be applied if the neutronic characteristics of the core are not affected significantly. Alternatively, a deterministic simulation model of the DNRR core is useful when the advantage in computational time is considered. In this respect, the WIMSD/CITATION codes were used to simulate the DNRR core and applied to the problem of incore fuel management [5].

In the present work, analysis models of the DNRR reactor have been developed using the SRAC deterministic code system [6]. Taking into account the advantage of the deterministic method, the SRAC code system allows simulating the DNRR core with small mesh sizes within reasonable computational time. The PIJ code of the SRAC system and the ENDF/B-VII.0 data library were used for lattice calculations to generate the macroscopic cross sections of fuel and nonfuel lattice cells. The full core was modelled using the COREBN code with hexagonal lattice cells. Numerical calculations have been conducted based on the core configuration loaded with $88 \mathrm{HEU}$ fresh fuel bundles. During the startup period of the DNRR core configuration of $88 \mathrm{HEU}$ fuel bundles, several criticality conditions were established with the control rod positions determined experimentally and reported in the startup report of the DNRR [7]. Therefore, in this work, the criticality calculations were analyzed and compared against the experimentally established conditions to verify the models. The effective multiplication factors, $k_{\text {eff }}$, were analyzed for two cases corresponding to the complete withdrawal and the full insertion of control rods (four shim rods and one automatic regulating rod). Criticality calculations of the DNRR were carried out with four different control rod banks determined during the experiments. Thermal neutron flux and power distributions have also been investigated throughout the radial core and along axial channels. In order to verify the analysis models, the results obtained with the MCNP5 code were compared to that obtained with the SRAC code system. Excess reactivity and the $k_{\text {eff }}$ values of the criticality calculations obtained using the codes are then compared to that reported in the startup report of the DNRR.

\section{Description of DNRR}

Figure 1 and Table 1 show the horizontal view and the specifications of the DNRR reactor [2]. The core consists of 121 hexagonal cells including fuel bundles, control rods, irradiation channels, and beryllium blocks. The VVR-M2 fuel bundle is made of aluminum-uranium alloy cladded in aluminum. The total ${ }^{235} \mathrm{U}$ mass in a HEU fuel bundle is about $40.2 \mathrm{~g}$ distributed in three coaxial fuel tubes. The outer tube has a hexagonal sharp appearance, and the two inner tubes are cylindrical. The reactor core is controlled by seven control rods: two safety rods (SR), four shim rods (ShR), and one automatic regulating rod (AR). The safety and shim rods are made of boron carbide $\left(\mathrm{B}_{4} \mathrm{C}\right)$, while the automatic regulating rod is made of stainless steel. The absorption length of the control rods is $65 \mathrm{~cm}$, which ensures completely covering the active core $(60 \mathrm{~cm})$. Dry channel and wet channel are covered by aluminum cylinders with the thickness of $0.5 \mathrm{~mm}$. The neutron trap at the center of the core is a water cylinder with $6.5 \mathrm{~cm}$ in diameter and $60 \mathrm{~cm}$ in length surrounded by six beryllium blocks. The beryllium block has the same outer shape and dimension as the fuel bundle. At several peripheral cells, if no fuel bundle is loaded, the beryllium blocks are loaded for providing supplementary neutron reflection. A beryllium ring of serrated beryllium blocks is located between the active core and the graphite reflector and serves as an additional reflector. This beryllium ring and the core are placed in a cylindrical aluminum shell, the lower section of the supporting structure. The thickness of the graphite reflector is $30.5 \mathrm{~cm}$. The core and the graphite reflector are placed into the reactor pool. In the present work, neutronics calculations have been performed based on the core configuration of $88 \mathrm{HEU}$ fuel bundles as illustrated in Figure 2.

\section{Calculation Models}

3.1. Description of the SRAC Code System. SRAC is a deterministic code system developed by Japan Atomic Energy Agency for neutronics calculations of both lattice physics and core physics of various reactor types [6]. The SRAC code system integrates three transport codes (PIJ, ANISN, and TWOTRAN) and two diffusion codes (TUD and CITATION) for neutron flux calculations. The PIJ code is based on the collision probability method which could simulate 16 different lattice geometries. An auxiliary code COREBN is also integrated for core burnup calculations. The COREBN consists of the CITATION and a function to interpolate macroscopic cross sections provided by lattice cell calculations. This interpolation function allows COREBN performing burnup calculations for various thermal reactors with strong heterogeneity which cannot be conducted using the original CITATION. In the present work, the PIJ and COREBN have been used for the lattice physics and core physics analyses of the DNRR, respectively. The cell averaged macroscopic cross sections of all material types are prepared in the lattice physics calculations using the PIJ code. The macroscopic cross sections are then calculated for core physics calculations using COREBN.

3.2. Lattice Calculations Using PIJ. The macroscopic cross sections of fuel cell, neutron trap, control rods, and other nonfuel lattice cells were prepared via lattice cell calculations using the PIJ code and ENDF/B-VII.0 data library $[6,8]$. For fuel cell, the hexagonal fuel bundle was modelled with a small geometrical modification of the outer hexagonal fuel tube of the VVR-M2 fuel bundle. Figure 3 shows the crosssectional views of the VVR-M2 fuel bundle and the fuel lattice cell model in the PIJ code along with the detailed dimensional parameters. The fuel bundle consists of three 


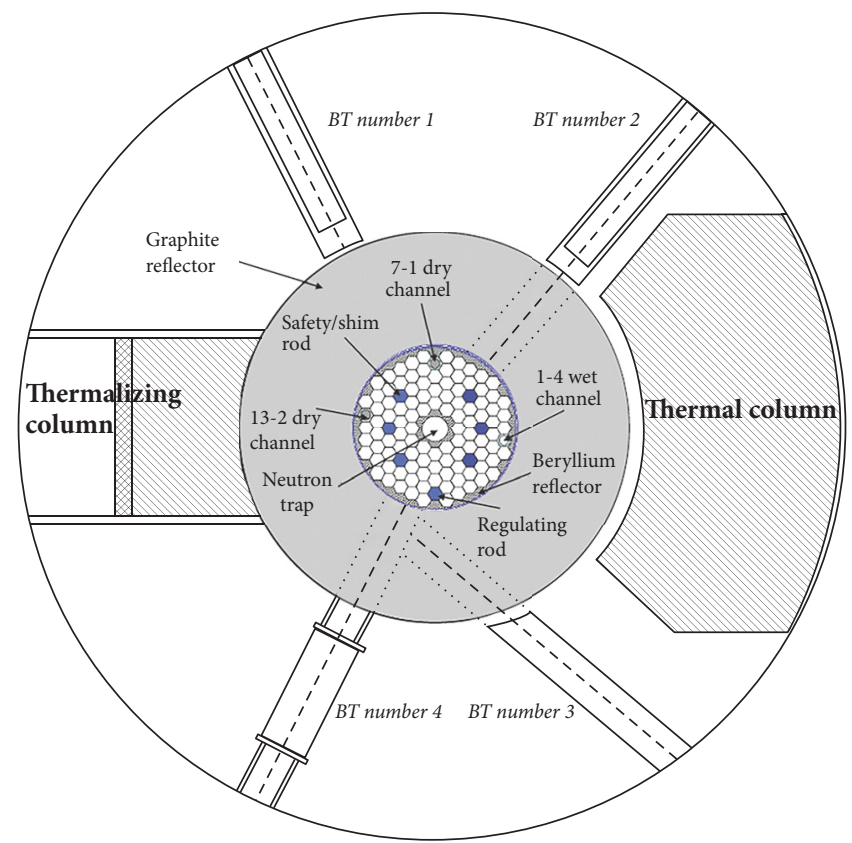

FIGURE 1: Horizontal view of the DNRR.

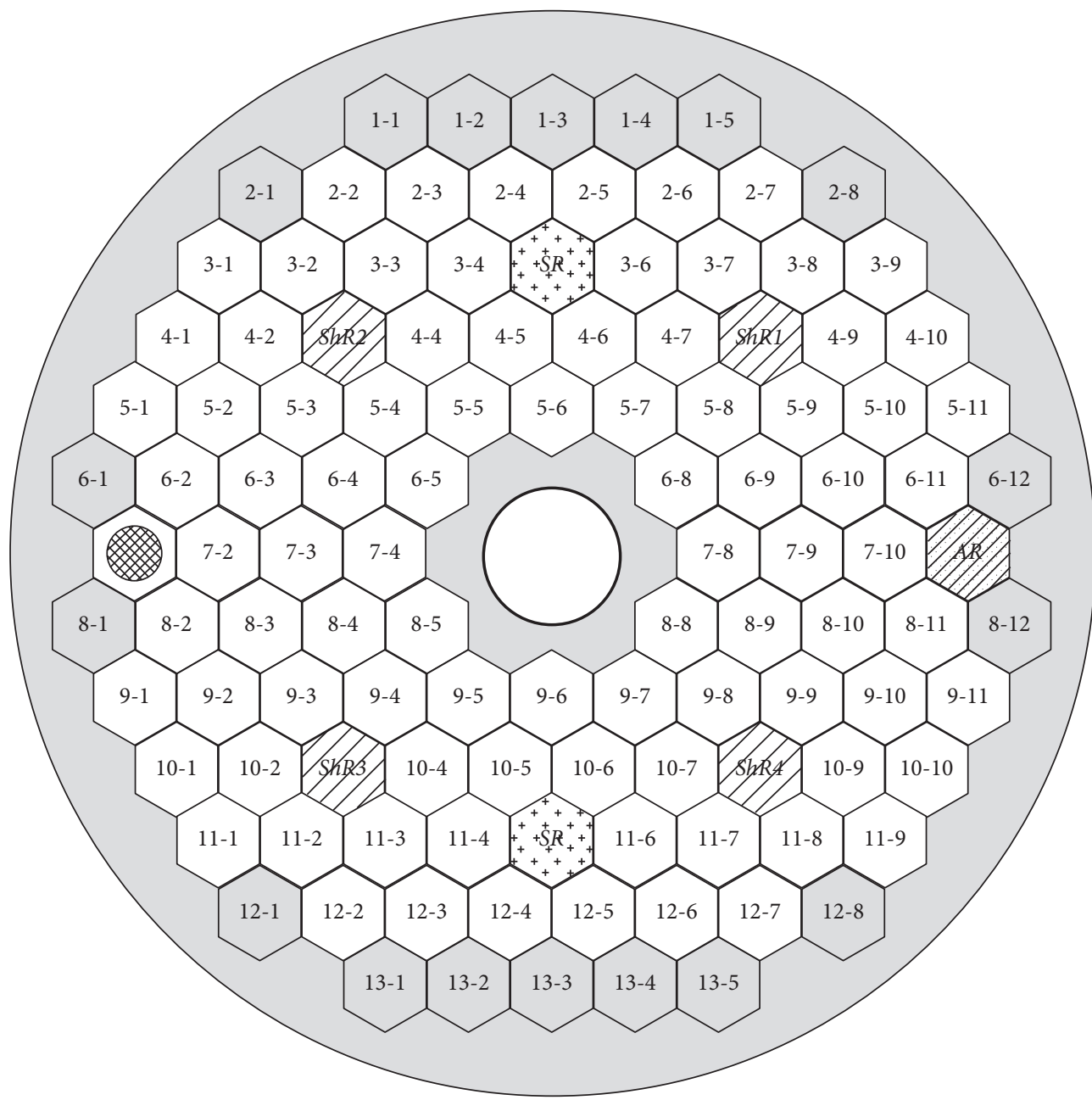

FIGURE 2: Configuration of the DNRR core with 88 HEU fuel bundles. SR: safety rod, ShR: shim rod, and AR: automatic regulating rod. 


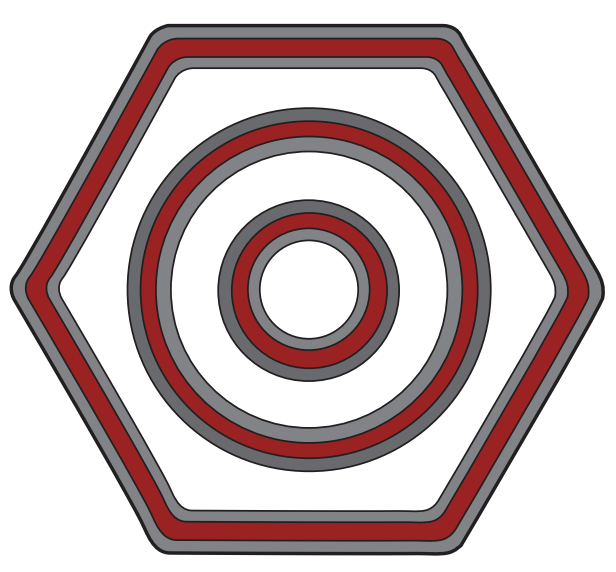

U-Al alloy (36\% U, 64\% Al) Aluminum (100\%)

(a)

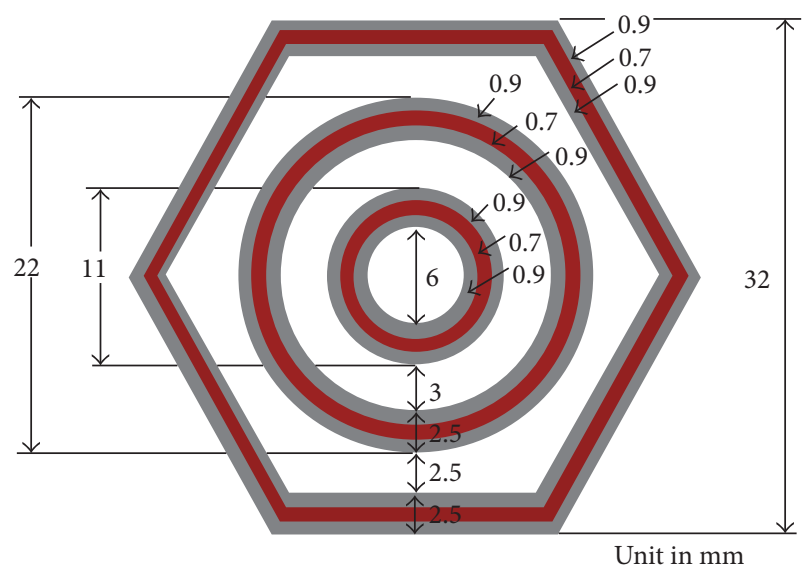

U-Al alloy (36\% U, 64\% Al)

Aluminum (100\%)

(b)

FIgURE 3: Horizontal cross sections of (a) the VVR-M2 fuel bundle and (b) the fuel lattice cell model in the PIJ code.

TABLE 1: Specifications of the DNRR.

Reactor type

Nominal thermal power

Coolant and moderator

Core cooling mechanism

Reflector

Active core height

Core equivalent diameter

Fuel pitch

Fuel type

Fuel meat

Fuel cladding

${ }^{235} \mathrm{U}$ enrichment

Number of control rods

Material of safety and shim rods

Material of automatic regulating rod

Neutron measuring channels

Vertical irradiation channels

Horizontal beam ports

\section{Pool type \\ $500 \mathrm{~kW}$ \\ Water}

Natural convection

Graphite, beryllium, water

$60 \mathrm{~cm}$

$44.2 \mathrm{~cm}$

$3.5 \mathrm{~cm}$

VVR-M2 type

U-Al alloy

Aluminum alloy

$36 \mathrm{wt} \%$

7 (2 safety rods, 4 shim rods, 1 regulating rod)

$$
\mathrm{B}_{4} \mathrm{C}
$$

Stainless steel

9 (6 CFC, 3 CIC)

4 (1 neutron trap, 1 wet channel, 2 dry channels) 4 (1 tangential, 3 radials) fuel tubes cladded by aluminum. The two inner tubes have cylindrical shapes, while the outer tube is hexagonal with six circular corners. However, since the PIJ code is not able to simulate exactly the circular corners of the outer hexagonal fuel tube of the VVR-M2 fuel bundle, a sharp hexagonal tube was assumed in the simulation model by preserving the total fuel mass. In the lattice calculations of the PIJ code, 107 energy groups' structure was used. Then, the cross sections were collapsed into seven energy groups (4 fast groups and 3 thermal groups) for full-core calculations.

The neutron trap consists of a cylindrical water hole surrounded by six beryllium blocks. Since SRAC does not allow simulating exactly the geometry of the neutron trap in the full-core model, the neutron trap is modelled as a hexagonal water cell at the center surrounded by six hexagonal blocks of homogeneous beryllium and water. Therefore, in the lattice calculation, the homogenization of beryllium and water at the six surrounding cells has been conducted while preserving the volume fractions of the beryllium and water. Calculating the cross sections of the safety and shim rods is more complicated due to the strong absorption of the control rods. Since the control rods are considered as black absorber materials, the extrapolated boundary constants corresponding to each neutron energy 


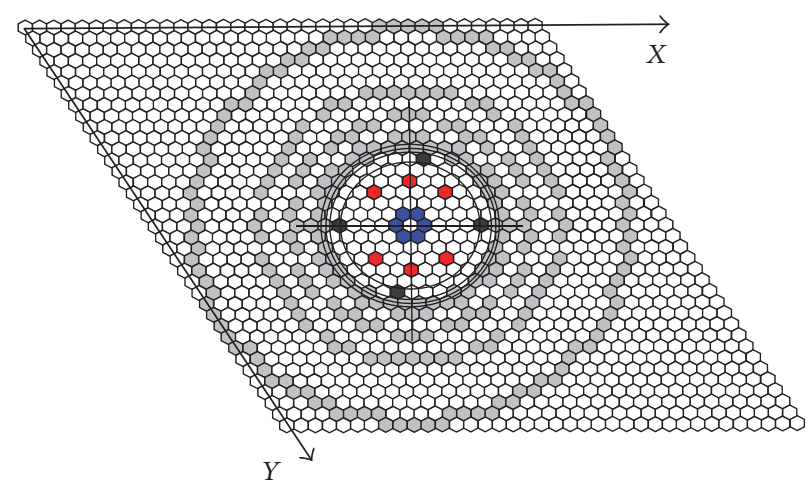

FIGURE 4: Full-core model with hexagonal grid.

group should be taken into account. Therefore, once the macroscopic cross sections of the control rods were obtained using PIJ, the ANISN code based on the Sn theory was used to determine the extrapolated length in each energy group. Other nonfuel lattice cells such as aluminum rod, beryllium rod, and regulating rod were also simulated using the PIJ code. The cross sections of materials in the active core were taken from the previous lattice cell calculations and inputted exactly at the same positions in the core model using PIJ (supercell calculation). Other lattice cells at the positions of the horizontal beam tubes, rotary specimen rack, and the interface regions were not calculated using the PIJ code, but the compositions (air, water, aluminum, and graphite) were homogenized and inputted in the full-core model.

3.3. Full-Core Model. The COREBN of the SRAC code system was used for the full-core calculation with hexagonal lattice cells [6]. The full-core model was described by hexagonal grids of $37 \times 37$ in the $X-Y$ plane as shown in Figure 4 . The total height of the model $(184.5 \mathrm{~cm})$ was axially divided into a number of layers so that each axial layer has the same material. For instance, the active core is axially divided into 60 layers with the mesh size about $1 \mathrm{~cm}$. However, the actual mesh size of each layer in the full-core models could be slightly changed depending on the position of control rods. The upper part of the beryllium blocks is water, and the lower part is the homogenization of aluminum and water.

3.4. Monte Carlo Model. Monte Carlo calculations of the DNRR have been performed using the MCNP5 code and ENDF/B-VII.0 data library to verify the analysis models and the results obtained with the SRAC code system. MCNP5 is a general Monte Carlo N-Particle transport code developed at Los Alamos National Laboratory [9]. MCNP5 has an ability to describe precisely the complex geometry of the DNRR including the fuel bundles, horizontal beam tubes, reflector, and thermal column and thermalizing column. To simplify the simulation model but not affecting significantly the neutronic characteristics of the DNRR core, the upper and lower parts of the fuel bundle, aluminum rod, beryllium rod, and dry and wet irradiation channels were described as the homogeneous mixtures of aluminum and water. Figure 5 displays the vertical and horizontal cross-sectional views of the DNRR core in the MCNP5 model. The model is expanded from the active core to reactor tank, following the radial direction with $198 \mathrm{~cm}$ in diameter and the axial direction with $184.5 \mathrm{~cm}$ in height. The history number of $210 \times 10^{6}$ was chosen so that the statistic error of $k_{\text {eff }}$ would be less than $0.006 \%$. Tallies 4 and 7 were used to calculate the neutron flux and power distributions.

Since the simulation requires a high computational resource, in the present work, the criticality calculations were performed on a Windows server with 80 CPUs. The computational time of each run for the mentioned history number is about 156 minutes. When the computational time of the codes is compared, the SRAC code is advantageous since it can run fast on a personal computer with Intel Core i54460 of CPU $3.3 \mathrm{GHz}$. Once the macroscopic cross sections of all materials are prepared using the PIJ code, the full-core calculation takes about half a minute.

\section{Numerical Calculations and Comparison with MCNP5}

4.1. Lattice Calculations. The infinite multiplication factor, $k_{\infty}$, of the fuel bundle obtained from the PIJ code is 1.64463 , greater than that obtained from MCNP5 $(1.64034 \pm 0.00004)$ by about $261 \mathrm{pcm}$. If the MCNP5 model uses the modified geometry of the outer fuel tube as in the PIJ model, the deviation of $k_{\infty}$ is about $139 \mathrm{pcm}$. This indicates that the lattice calculation results of the codes have a good agreement.

4.2. Criticality Calculations. The $k_{\text {eff }}$ values obtained are shown in Table 2. It can be seen that, in the case of control rod withdrawal, the $k_{\text {eff }}$ values of 1.08633 and 1.08632 were obtained from the SRAC and MCNP5 calculations, respectively. The calculated values are well consistent with each other. Taking into account the fact that the effective delayed neutron fraction, $\beta_{\mathrm{eff}}$, of the core is 0.0081 , the $k_{\text {eff }}$ values correspond to the excess reactivity of about $9.81 \$$. This value is comparable with that $(9.85 \$)$ reported in the startup report of the DNRR [7]. The leakage reactivity penalty is -0.01940 , and that associated with absorption is -0.90114 . In the case of full insertion of the four shim rods and the automatic regulating rod, the difference of the $k_{\text {eff }}$ values is about $242 \mathrm{pcm}$. This agreement between the SRAC and 


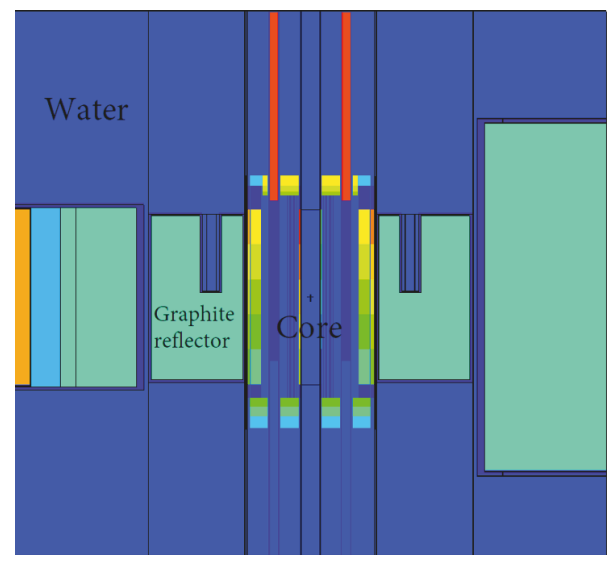

(a) Vertical

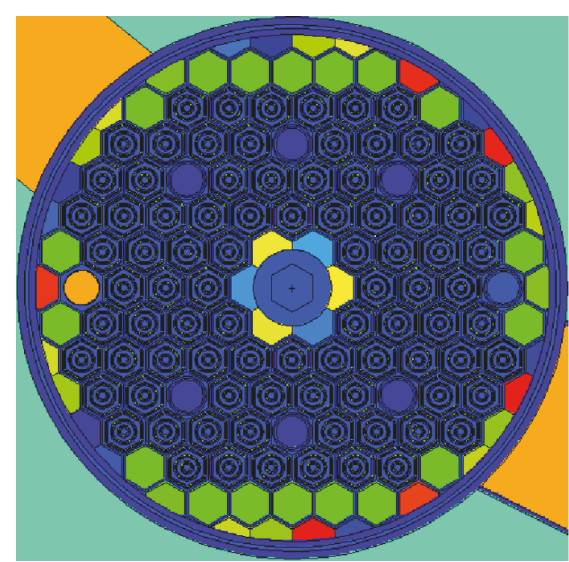

(b) Horizontal

FIGURE 5: Vertical and horizontal cross sections of the DNRR in the MCNP5 model.

TABLE 2: The $k_{\text {eff }}$ in the cases of complete withdrawal and full insertion of control rods.

\begin{tabular}{lccc}
\hline Code & $k_{\text {eff }}(\mathrm{A})$ & $k_{\text {eff }}(\mathrm{B})$ & Reactivity worth $\left(\% \Delta k / k k^{\prime}\right)$ \\
\hline SRAC & 1.08633 & 0.98029 & 9.96 \\
MCNP5 & $1.08632 \pm 0.00006$ & $0.97787 \pm 0.00005$ & 10.21 \\
\hline
\end{tabular}

(A) All control rods are completely withdrawn. (B) Two safety rods are withdrawn; four shim rods and the automatic regulating rod are fully inserted.

MCNP5 calculations gives a certain confidence for further analysis of the DNRR core. The total worth values of the four shim rods and the automatic regulating rod of $12.3 \$$ and $12.6 \$$ obtained from SRAC and MCNP5, respectively, are sufficient to shut down the reactor.

Criticality calculations of the core with four control rod banks have been carried out. To do this, the four shim rods were inserted into the core. Then, the position of the AR was adjusted to obtain the criticality of the core. These criticality conditions were achieved during the startup of the DNRR core with HEU fuel [7]. Since the two safety rods are used only for emergency shutdown, in all cases they were assumed to be completely withdrawn.

Table 3 shows the results of the criticality calculations corresponding to the four control rod banks. The $k_{\text {eff }}$ values are closed to unity with the deviation within $119 \mathrm{pcm}$. In all cases, the $k_{\text {eff }}$ values obtained for SRAC are in good agreement with that obtained from MCNP5 calculations. The greatest difference is about $55 \mathrm{pcm}$ corresponding to the case with the insertions of ShRs $=45 \mathrm{~cm}$ and $\mathrm{AR}=65 \mathrm{~cm}$. Compared to unity, that is, the criticality conditions established in the experiments [7], the maximum difference of the $k_{\text {eff }}$ values obtained from the SRAC calculations is $119 \mathrm{pcm}$, while this value is $64 \mathrm{pcm}$ for the MCNP5 calculations. This agreement compared to the experiments indicates the verification of the models.

\subsection{Power and Thermal Neutron Flux Distributions. Thermal} neutron flux and power distributions of the DNRR core have been analyzed in detail for two cases corresponding to the complete withdrawal and the partial insertion $(\mathrm{ShR}=$ $45.7 \mathrm{~cm}$ and $\mathrm{AR}=40 \mathrm{~cm}$ ) of control rods in comparison with
MCNP5 calculations. Figure 6 shows the radial relative power distribution at the initial critical condition corresponding to the control rod insertions of $\mathrm{ShR}=45.7 \mathrm{~cm}$ and $\mathrm{AR}=$ $40 \mathrm{~cm}$. The radial power peaking factor is 1.445 which appears at the fuel bundle 9-6. This value is obtained as 1.486 in the MCNP5 calculation. The deviation of the relative power densities between the codes is less than $4 \%$ at most of fuel bundles, except some bundles located at periphery where the maximum deviation is about $7 \%$. Figure 7 is similar to Figure 6 but for the case of complete withdrawal of all control rods. The radial power peaking factor is about 1.334 at the fuel cell 9-6 obtained with SRAC, smaller than that obtained with MCNP5 (1.385) by about 3.7\%.

Figures 8 and 9 depict the axial power distributions at the fuel cells 9-6 and 7-10 in the cases of control rod insertion and control rod withdrawal, respectively. The fuel cell 9-6 corresponds to the highest power rating. The fuel cell 7-10 is located close to the AR, and, therefore, its power profile and flux distribution show clearly the effect of control rod insertion. When the control rod is partially inserted, the power profile is shifted to the lower half of the core, and the power peaking factor increases. The axial power peaking factor is about 1.710 in the case of control rod withdrawal, while it is about 1.832 in the case of control rod insertion. Furthermore, axial power profile results of the codes are in good agreement. The largest difference is found at the boundary interfaces between the active fuel and the upper and lower reflectors.

Figures 10 and 11 show the axial thermal neutron flux distribution in the fuel cells 9-6 and 7-10 for the two cases corresponding to the control rod insertion and withdrawal, respectively. Figure 12 shows the axial distribution of the thermal neutron flux along the height of neutron trap in 
TABLE 3: Criticality calculations of the DNRR with four control rod banks.

\begin{tabular}{lccccccc}
\hline \multicolumn{4}{c}{ Position of control rods $(\mathrm{cm})$} & \multicolumn{2}{c}{} & \multicolumn{2}{c}{$k_{\text {eff }}$} \\
ShR1 & ShR2 & ShR3 & ShR4 & AR & SRAC & MCNP5 & 55 \\
\hline 45 & 45 & 45 & 45 & 65 & 1.00119 & $1.00064 \pm 0.00006$ \\
47.2 & 47.2 & 47.2 & 47.2 & 0 & 0.99960 & $0.99969 \pm 0.00006$ \\
45.7 & 45.7 & 45.7 & 45.7 & 40 & 1.00086 & $1.00051 \pm 0.00006$ \\
46.7 & 46.7 & 46.7 & 46.7 & 20 & 1.00009 & $0.99998 \pm 0.00006$ \\
\hline
\end{tabular}

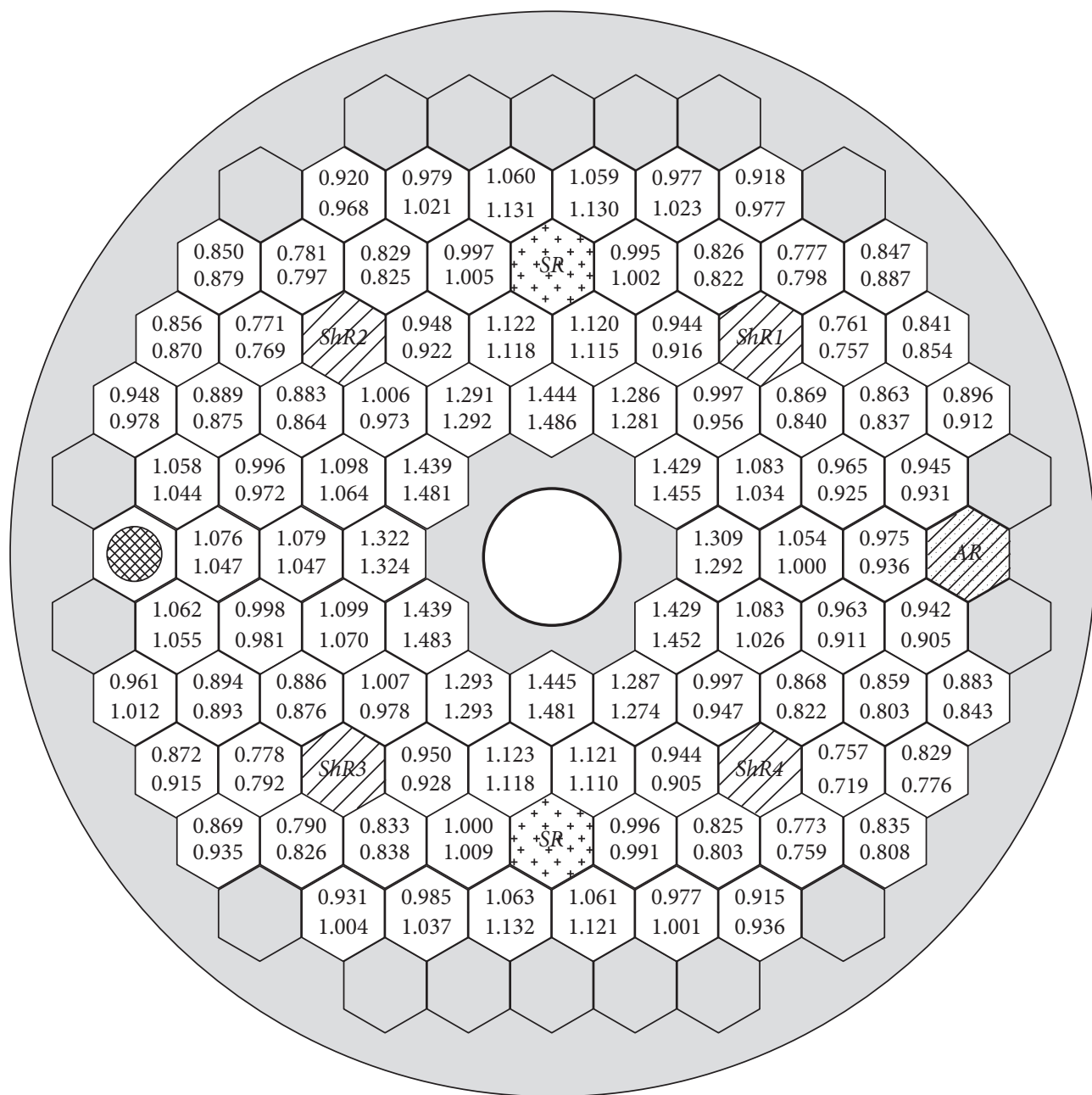

FIGURE 6: Relative power distribution in the core at the initial critical condition corresponding to the control rod insertion: $\mathrm{ShR}=45.7 \mathrm{~cm}$; $\mathrm{AR}=40 \mathrm{~cm}$. The upper and lower values were obtained with SRAC and MCNP5, respectively.

comparison with the results obtained from the MCNP5 calculations. It can be seen that the maximum thermal neutron flux is about $2.17 \times 10^{13} \mathrm{n} / \mathrm{cm}^{2} \cdot \mathrm{s}$ in the case of control rod withdrawal. The axial flux distribution is also shifted to the lower part of the core when the control rods are inserted. In this case, the peak value of thermal flux is about $2.38 \times$ $10^{13} \mathrm{n} / \mathrm{cm}^{2} \cdot \mathrm{s}$, shifted to about $10 \mathrm{~cm}$ from the central point of the neutron trap to the core bottom as shown in Figure 12, noting that there is a good agreement between the two codes. This indicates the validity of the analysis models and the potential use for further applications.
Since the DNRR core contains many complicated components, it is a challenge to model the core using a deterministic code. Homogenization of materials, especially in particular regions where control rods are withdrawn, could affect the accuracy of the results. However, in the present work, the analysis results show an acceptable agreement between the codes as well as the startup report. The current models of the DNRR core in the SRAC code could handle flexible axial mesh sizes along the core height depending on the actual control rod positions. A possible improvement of the models to handle finer radial meshes such as triangular meshes could 


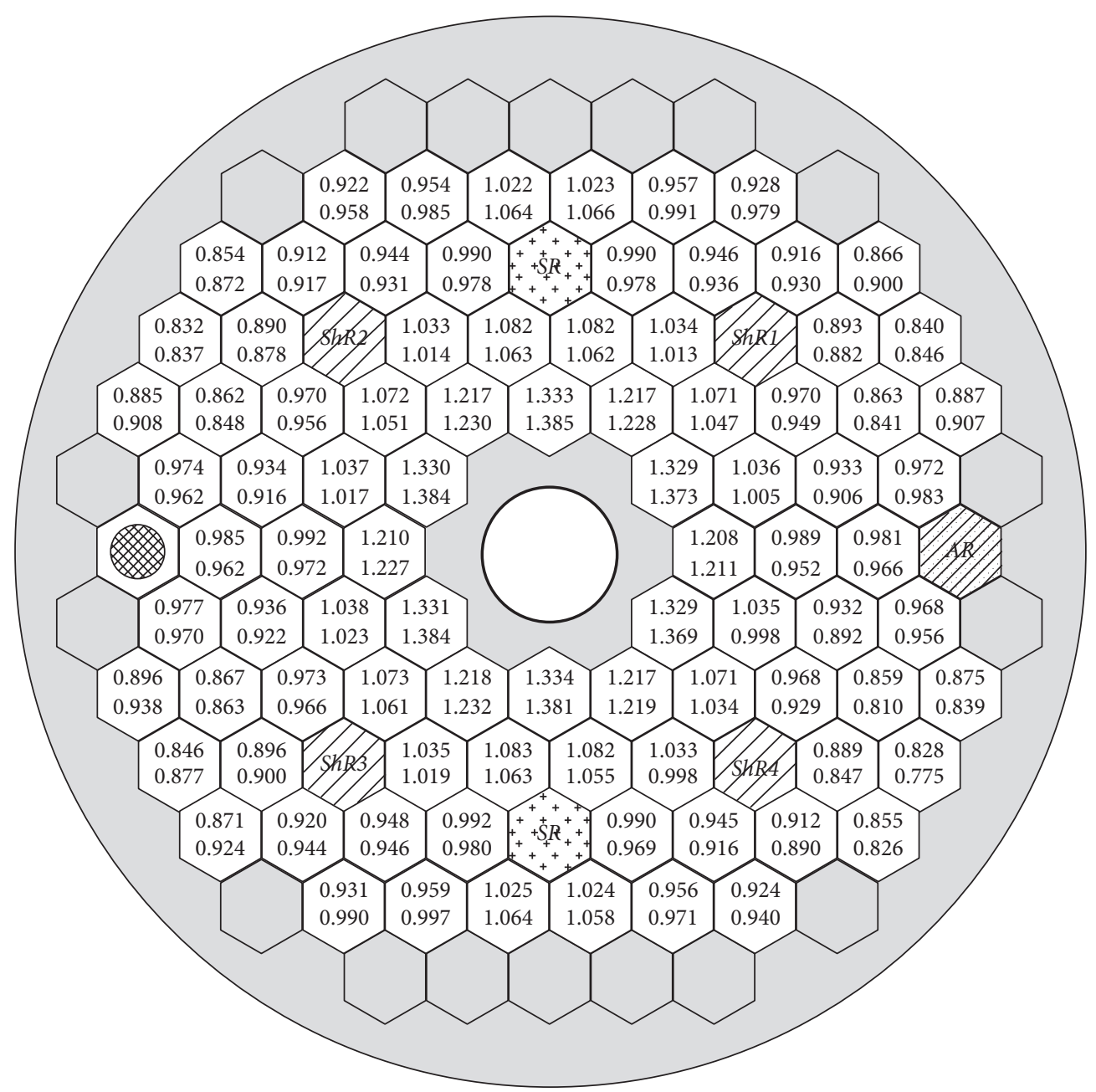

FIGURE 7: Relative power distribution in the case of complete withdrawal of the control rods. The upper and lower values were obtained with SRAC and MCNP5, respectively.

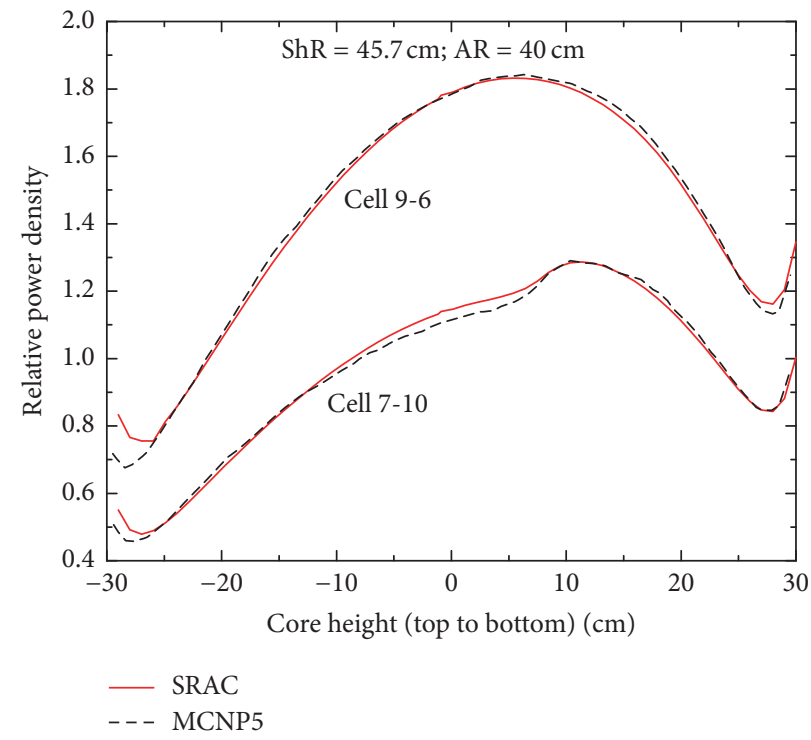

FIGURE 8: Axial power distribution along the fuel bundles 7-10 and 9-6 at the critical core condition corresponding to the insertion of control rods $\mathrm{ShR}=45.7 \mathrm{~cm}$ and $\mathrm{AR}=40 \mathrm{~cm}$. 


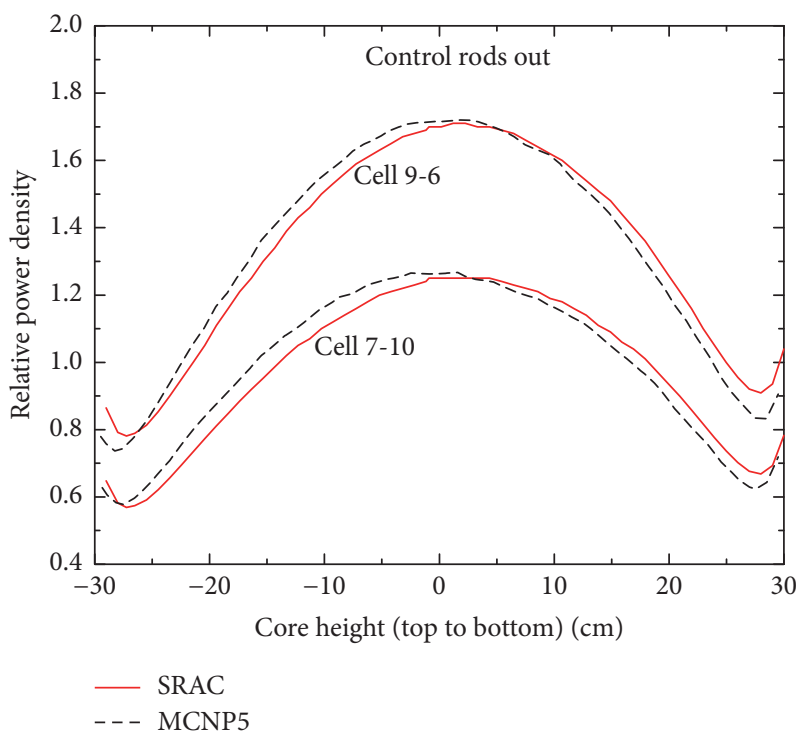

FIgURE 9: Axial power distribution along the fuel bundles 7-10 and 9-6 in the case of complete withdrawal of control rods.

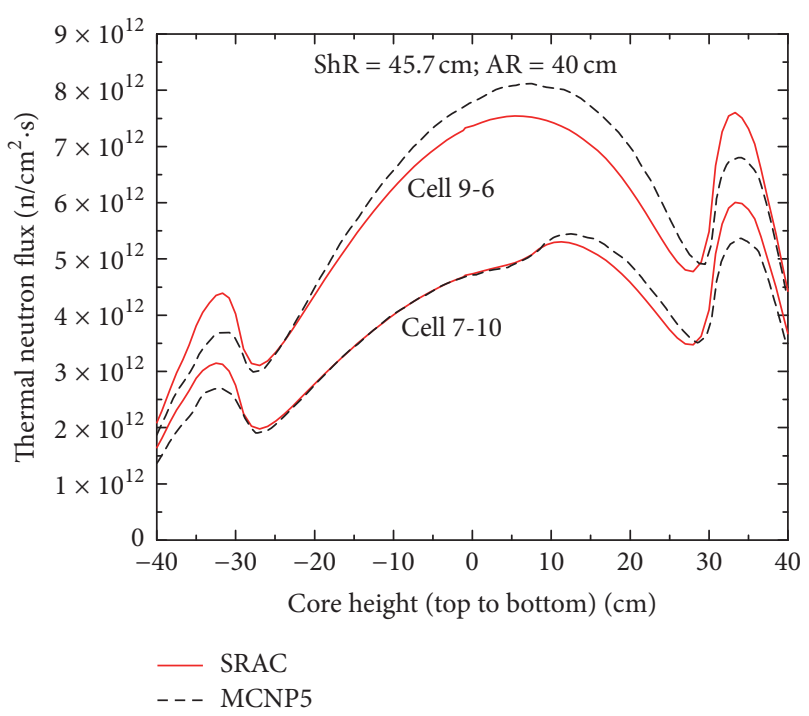

FIgURE 10: Thermal neutron flux distribution along the fuel bundles 7-10 and 9-6 at the critical core condition corresponding to the insertion of control rods $\mathrm{ShR}=45.7 \mathrm{~cm}$ and $\mathrm{AR}=40 \mathrm{~cm}$.

be useful to improve the accuracy of the calculation results. Further analyses are necessary to verify the models using both SRAC and MCNP5 codes for burnup and rod worth analyses of the DNRR core in comparison with the measurement data. Evaluation of the effect of the cross section data libraries on the neutronic properties of the DNRR core is being investigated. Application in analyzing the current working configurations of the DNRR with low enriched uranium (LEU) fuel bundles is also being planned.

\section{Conclusions}

Neutronics model of the DNRR was developed using the SRAC code system. The PIJ and COREBN codes of the

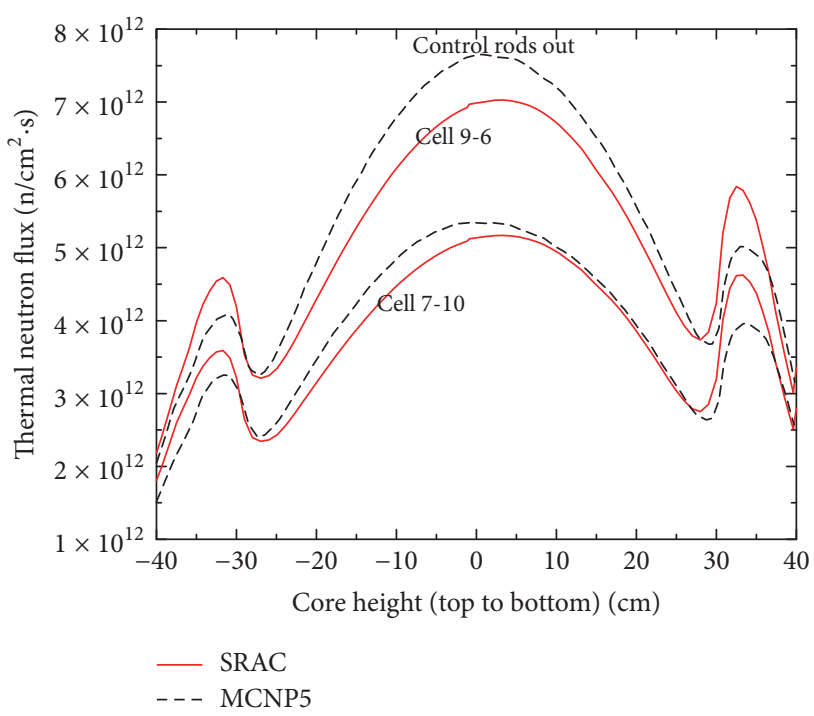

FIgURE 11: Thermal neutron flux distribution along the fuel bundles 7-10 and 9-6 in the case of complete withdrawal of control rods.

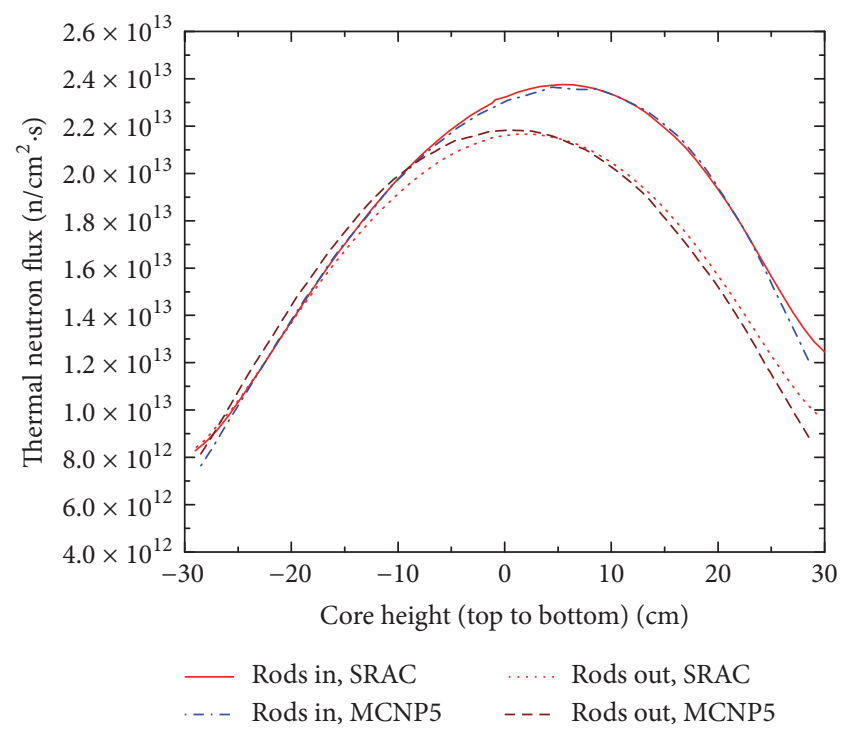

FIGURE 12: Thermal neutron flux distribution along the neutron trap. Rods in: $\mathrm{ShR}=45.7 \mathrm{~cm}$ and $\mathrm{AR}=40 \mathrm{~cm}$; Rods out: $\mathrm{ShR}=0 \mathrm{~cm}$ and $\mathrm{AR}=0 \mathrm{~cm}$.

SRAC code system were used for lattice physics and full-core analyses. In order to handle the complicated geometries of the DNRR such as the neutron trap, neutron channels, and upper and lower parts of the active core, homogenization has been conducted. Numerical calculations were performed to analyze the effective multiplication factors, $k_{\text {eff }}$, for two cases corresponding to the complete withdrawal and the full insertion of control rods. Criticality analyses were then conducted with the four different control rod banks. The radial and axial power peaking factors of the DNRR core are calculated to be 1.334 and 1.710, respectively, in the case of no control rod insertion. These values are 1.445 and 1.832 at the criticality condition with the partial insertion of control rods. Comparing to the MCNP5 calculations, the results show that 
the difference between the $k_{\text {eff }}$ values of the codes is less than $55 \mathrm{pcm}$. The maximum deviations of the $k_{\text {eff }}$ values obtained from SRAC and MCNP5 compared to the experiments are $119 \mathrm{pcm}$ and $64 \mathrm{pcm}$, respectively. The deviation of the relative power distributions between the codes is less than $4 \%$ for most of the fuel bundles in the middle of the core, while the maximum deviation is about $7 \%$ which appears at peripheral bundles. In addition, thermal neutron flux distributions in the neutron trap are in good agreement. This agreement indicates the verification of the models and the possibility for further analysis.

\section{Conflicts of Interest}

The authors declare that there are no conflicts of interests regarding the publication of this paper.

\section{Acknowledgments}

This research is funded by Foundation for Science and Technology Development of Ton Duc Thang University (FOSTECT), website: http://fostect.tdt.edu.vn/, under Grant FOSTECT.2016.BR.13.

\section{References}

[1] TRIGA History, URL: http://www.ga.com/triga-history.

[2] N. D. Nguyen, Ed., Safety Analysis Report for the Dalat Nuclear Research Reactor, Nuclear Research Institute, Vietnam Atomic Energy Commission, 2009.

[3] N. D. Nguyen, B. V. Luong, V. V. Le et al., "Results of Operation and Utilization of the Dalat Nuclear Research Reactor," Nuclear Science and Technology, vol. 4, no. 1, pp. 1-9, 2014.

[4] M. Türkmen and Ü. Çolak, "Analysis of ITU TRIGA Mark II research reactor using Monte Carlo method," Progress in Nuclear Energy, vol. 77, pp. 152-159, 2014.

[5] B. Q. Do and L. P. Nguyen, "Application of a genetic algorithm to the fuel reload optimization for a research reactor," Applied Mathematics and Computation, vol. 187, no. 2, pp. 977-988, 2007.

[6] K. Okumura, T. Kugo, K. Kaneko, and K. Tsuchihashi, SRAC2006: A Comprehensive Neutronics Calculation Code System, JAEA-Data/Code 2007-004, 2007.

[7] D. H. Pham, Q. H. Ngo, H. L. Vu, and K. M. Tran, Report startup of nuclear research reactor: Part 2 - Physics startup for core configuration with a neutron trap, Nuclear Research Institute, 1984.

[8] M. B. Chadwick, P. Obložinský, M. Herman et al., "ENDF/BVII.0: next generation evaluated nuclear data library for nuclear science and technology. Nucl. Data Sheets," Special Issue on Evaluated Nuclear Data File ENDF/B-VII.0, 2006.

[9] X-5 Monte Carlo Team, 2005. MCNP - A General Monte Carlo N-Particle Transport Code. Version 5. LA-UR-03-1987, April 24, 2003. 


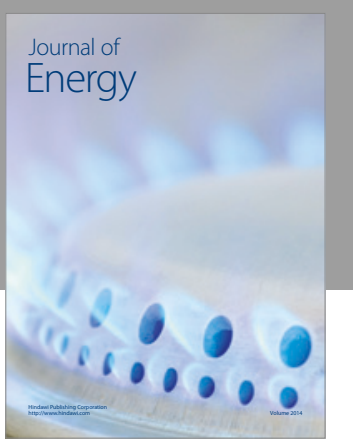

Journal of

Industrial Engineering
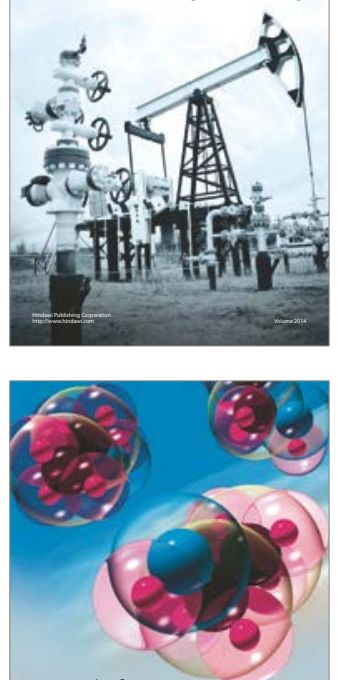

Fuels
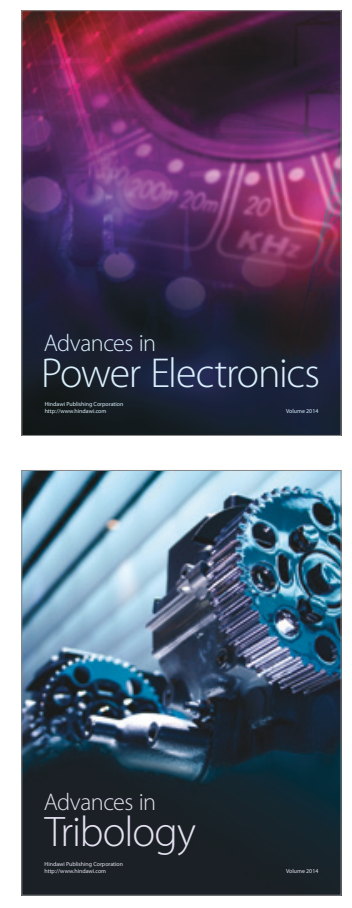
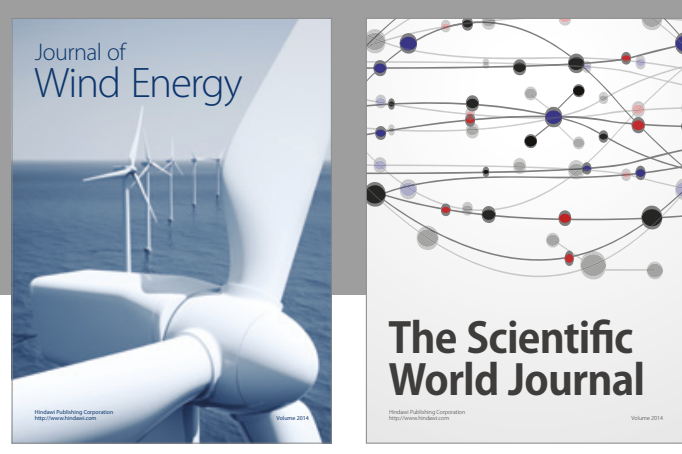

The Scientific World Journal
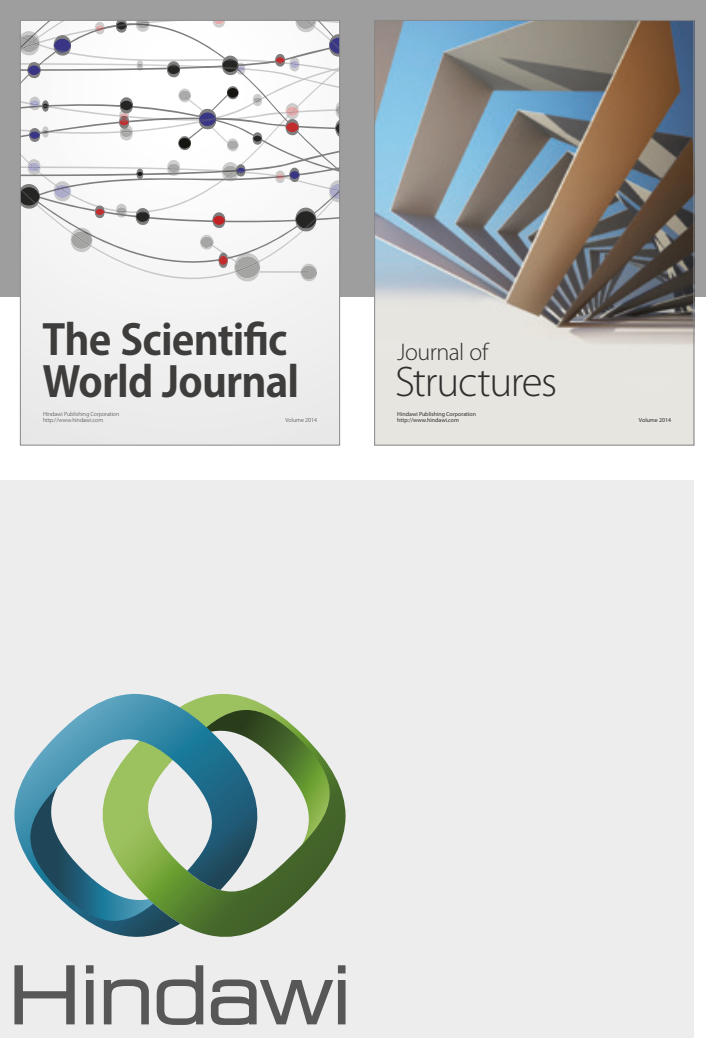

Submit your manuscripts at

https://www.hindawi.com
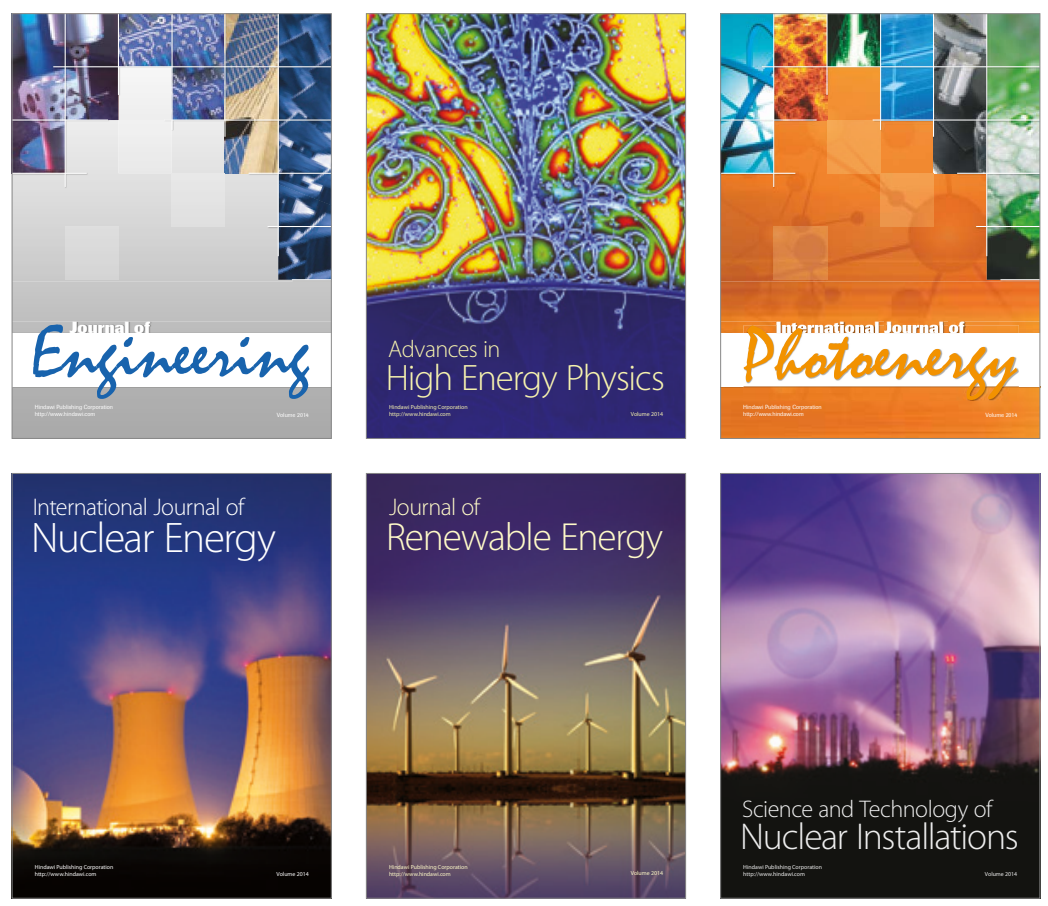

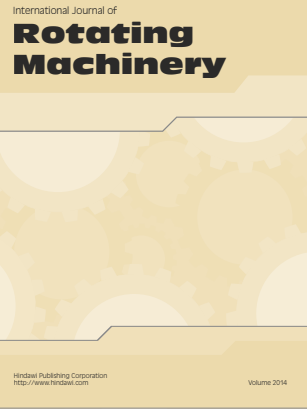

Journal of

Petroleum Engineering

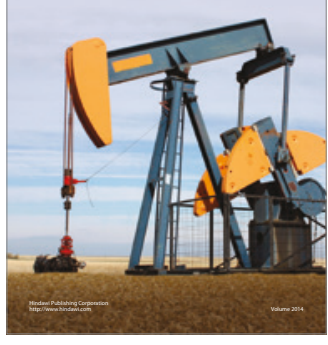

Journal of
Solar Energy
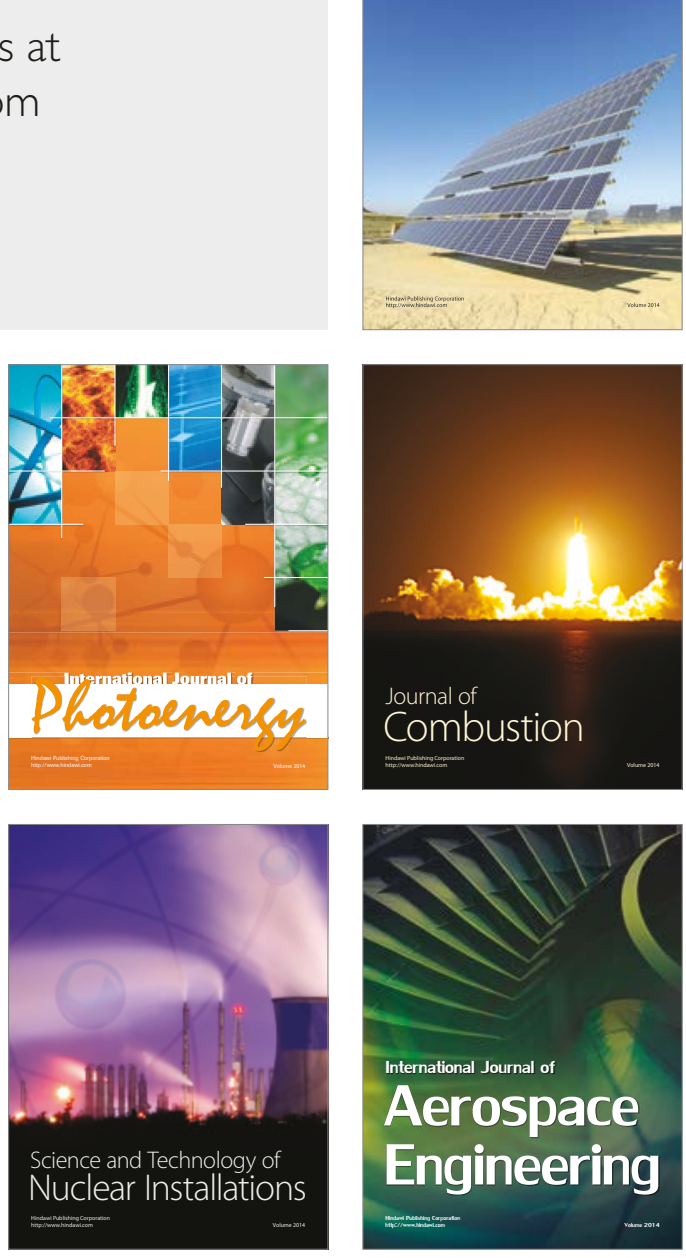